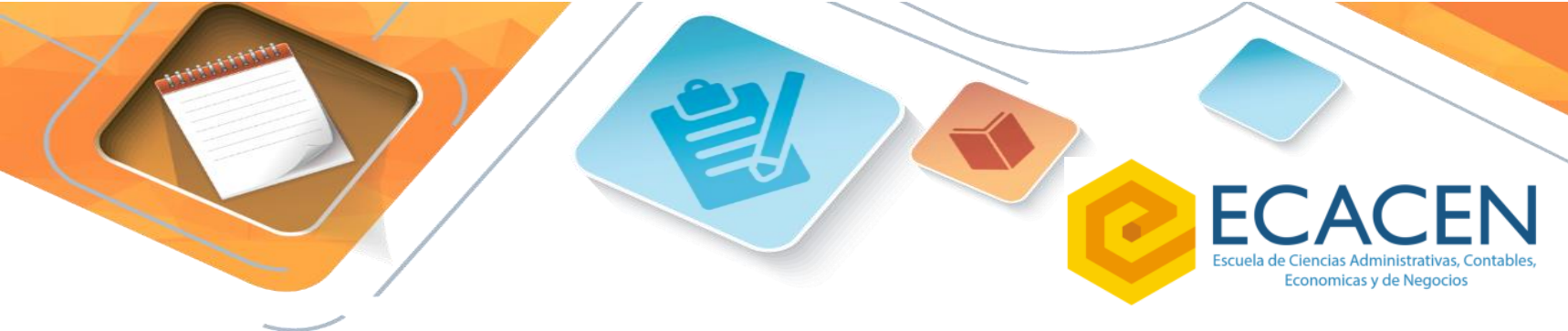

\title{
MEJORAMIENTO DE LA PRODUCTIVIDAD EN LAS EMPRESAS COLOMBIANAS: UN PROBLEMA DE PLANEACIÓN ESTRATÉGICA
}

\section{IMPROVEMENT OF PRODUCTIVITY IN COLOMBIAN COMPANIES: \\ A STRATEGIC PLANNING PROBLEM}

\author{
Luz Elena Montoya Rendón ${ }^{1}$ \\ Julio Cesar Montoya Rendón² \\ Carlos Rubén Trejos Moncayo 3
}

\section{Resumen}

El entorno empresarial en los tiempos actuales es de permanente atención de los skateholders y los riesgos asociados al bienestar de las organizaciones parecería que no están siendo debidamente encausado en su planeación estratégica y es así como, tanto en Colombia como en otras regiones Latinoamericanas, en los últimos quince años se viene presentando baja en la productividad de las empresas. Este problema requiere atención, puesto que incide directamente en el crecimiento sostenible de beneficios sociales y económicos no solo de las organizaciones sino de la calidad de vida de las personas y en consecuencia del Estado. Identificar los factores a tener en cuenta en el

\footnotetext{
${ }^{1}$ Administradora de Empresas, Maestría en Administración de Empresas con Énfasis en Sistemas Integrados de Gestión. Investigador asociado del Grupo de Investigación Ilama. Docente de la Universidad Nacional Abierta y a Distancia - UNAD, Colombia. luz.montoya@unad.edu.co

2 Administrador de Empresas, Especialista en Pedagogía para el Desarrollo del Aprendizaje Autónomo, Maestría en Administración de Empresas. Investigador junior del Grupo de Investigación Ilama. Docente de la Universidad Nacional Abierta y a Distancia - UNAD, Colombia. ORCID https://orcid.org/0000-0003-11709296 Google Scholar: https://scholar.google.es/citations?user=JGJcuGwAAAAJ\&hl=es Correo electrónico de contacto: julio.montoya@unad.edu.co

${ }^{3}$ Administrador de Empresas, Especialista en Gerencia Estratégica de Mercadeo, Magister en Mercadeo Agroindustrial, Docente de la Escuela de Ciencias Administrativas Contables Económicas y de Negocios ECACEN de la UNAD, investigador grupo Sindamanoy, líneas de investigación: emprendimiento y cadenas productivas. Correo electrónico carlos.trejos@unad.edu.co, C.C. No. 98394180 de Pasto. Código ORCID http://orcid.org/0000-0003-0352-9981
} 
indica que la cantidad de producción varía en relación con la cantidad de recursos utilizados en el proceso

$$
\text { Productividad }=\frac{\text { Cantidad de productos o servicios realizados }}{\text { Cantidad de recursos utilizados }}
$$

Además, existe otro procedimiento para medir la productividad de un periodo, es el multifactor, el cual se considera un punto de partida para que la gerencia esté atenta a su comportamiento y según sea, reemplazar factores que provean un mayor nivel de productividad Este procedimiento tiene en cuenta los siguientes factores básicos: capital, materiales, mano de obra directa y gastos generales, tal como se visualiza en las siguientes relaciones establecidas por Sampayo \& Reyes (2016):

\section{Factor}

Fórmula

Capital

$$
\text { Capital : } \frac{\text { Volumen de productos producidos }}{\text { Valor de los activos }}
$$

Materiales

$$
\text { Materiales : } \frac{\text { Volumen de productos producidos }}{\text { Dinero desembolsado en materiales }}
$$

Mano de obra directa Mano de obra directa: $\frac{\text { Volumen de productos producidos }}{\text { Horas de mano de obra directa }}$

Gastos generales

$$
\text { Gastos generales : } \frac{\text { Volumen de productos producidos }}{\text { Dinero desembolsado en gastos generales }}
$$

Fuente: Sampayo \& Reyes, 2016

A manera de conclusión, se identificaron factores externos y externos que desde la política pública influencian el qué hacer de la alta dirección de las organizaciones y 
sector manufacturero chileno. Economía Institucional, volumen 18(35), pp. 229255. Recuperado de:

https://www.economiainstitucional.com/esp/vinculos/pdf/No35/13candia35.pdf

Fred R., David (2013). Administración estratégica. Ciudad de México: México. Pearson Educación.

Joseph Prokopenko (1992). Productivity Management: A practical handbook, Recuperado de:

https://books.google.com.co/books?id=0jyOKj8S_iYC\&printsec=frontcover\&hl= es\&source=gbs_ge_summary_r\&cad $=0 \# v=$ onepage $\& q \& f=$ false

Sampayo, C.A. \& Reyes, M.A. (2016). Factores que contribuyen en la productividad de los frutales de tardío rendimiento cultivados por pequeños agricultores en Palmira, Valle del Cauca. Tesis de pregrado. Universidad Santiago de Cali. Palmira.

Gutiérrez, H. (2010). Calidad total y productividad. Recuperado de: http://www.academia.edu/10265514/Calidad-total-y-productividad-3ediGutierrez_Pulido 